\title{
Macrofollicular Variant Thyroid Gland Papillary Carcinoma
}

National Cancer Institute

\section{Source}

National Cancer Institute. Macrofollicular Variant Thyroid Gland Papillary Carcinoma. NCI

Thesaurus. Code C46092.

A morphologic variant of papillary carcinoma of the thyroid gland characterized by the predominance or the exclusive presence of macrofollicles. Some of the malignant follicular cells display the nuclear features that characterize the papillary adenocarcinomas of the thyroid gland. 